\title{
Genetic Diversity and Population Structure of Sardinian Myrtle (Myrtus communis L.) Selections as Obtained by AFLP Markers
}

\author{
Sara Melito \\ Department of Agriculture, University of Sassari, 07100 Sassari, Italy
}

Angela Fadda ${ }^{1}$

Institute of Science of Food Production, National Research Council, 07100

Sassari, Italy

Emma Rapposelli

Department for Fruit and Forestry Research of AGRIS-Sardinia, Cagliari, Italy

\author{
Maurizio Mulas \\ Department of Nature and Land Sciences, Via De Nicola 9, University of \\ Sassari, Italy
}

Additional index words. cultivar, domestication, germplasm, molecular markers

\begin{abstract}
Myrtle is an aromatic plant typical of the Mediterranean maquis. It is widely exploited in pharmaceutical, cosmetic, and food industries, whereas in Italy, it is mainly used for the production of the typical liqueur. Amplified fragment length polymorphism (AFLP) markers were used to evaluate the genetic variability of some Sardinian Myrtus communis L. candidate cultivars. The AFLP selective amplification produced 138 reproducible AFLP fragments, $96 \%$ of which were polymorphic. STRUCTURE analysis divided the myrtle accessions into two main genetic groups $(K=2)$. The two clusters showed different numbers of individuals. Most of the individuals belonged to Cluster $B$, whereas only eight genotypes were attributed to Cluster A. Unweighted pair group method with Arithmetic Mean (UPGMA) dendrogram segregated all the myrtle cultivars into five main groups, displaying a partial congruence with the division observed by STRUCTURE analysis. The analysis of the genetic diversity distribution in a candidate cultivar selection displayed a geographical gradient of myrtle from north to south, which reflects the Sardinian shape, and from west to east, which reflects the Sardinian mountain distribution.
\end{abstract}

Myrtle (Myrtus communis L.) is an evergreen shrub typical of the Mediterranean maquis. Myrtle is an aromatic plant rich in essential oils used in pharmaceutical, cosmetic, and food industries. Its characteristics have long been known; in the past, myrtle was used as flavoring agent and in folk medicine for its anti-inflammatory and antiseptic properties. The medical literature have confirmed the antimicrobial properties (Deriu et al., 2007; Gündüz et al., 2009) and assessed the apoptotic activity against cancer cells of myrtucommulone, a nonprenylated acylphloroglucinol present in myrtle leaves (Tretiakova

Received for publication 12 Nov. 2013. Accepted for publication 15 Mar. 2014.

The research was supported by the PYRGI project of the European Union (Special Grant Italy-France 'Marittimo') and by Regione Autonoma della Sardegna (Special Grant LR 7/2007-2012: “The myrtle: genetics and metabolomics, an integrated approach for industry development"; and Postdoctoral Fellowship "Master and Back" program 2011).

${ }^{1}$ To whom reprint requests should be addressed; e-mail angela.fadda@ispa.cnr.it. et al., 2008). Furthermore, recent data highlighted the good antioxidant properties of myrtle berry extracts and their use as food preservatives was also suggested (Tuberoso et al., 2010). In the last years, myrtle has been appreciated as an ornamental plant as a result of the new interest of consumers in Mediterranean flora. Despite its manifold uses, in Sardinia, myrtle plant is mainly associated with the typical liqueur that is produced through maceration of its berries and leaves. At present, the production of the myrtle liqueur accounts for $\approx 4$ million liters per year (homemade and industry production) but it is steadily increasing because of its success at the national and international levels (Mulas, 2012). The enhanced interest on myrtle liqueur as well as the restriction for certified producers to use only Sardinian myrtle has given rise to an increase in the demand for Sardinian raw material. At present, the bulk of the raw material comes from natural populations, which are therefore increasingly subjected to human pressure and genetic erosion (Mulas et al., 1999; Mulas and Deidda, 1998). In the last 10 years a domestication program has been carried out with the aim to supply to both the liqueur and pharmaceutical industries raw material with known characteristics and to preserve the natural populations (Mulas and Deidda, 1998; Mulas and Cani, 1999). With these purposes, some ecotypes, interesting for biomass and fruit production, were collected from Sardinian natural populations and planted in a repository at the "Antonio Milella" experimental station of the University of Sassari, in central-western Sardinia (Mulas, 2012; Mulas et al., 2002).

Germplasm genetic identification and characterization is an important step for the conservation and the use of plant genetic resources. DNA-based markers have been widely used to assess the genetic diversity of plant cultivars (Amar et al., 2011; Kalia et al., 2011; Osman et al., 2012) and to study the relationships among the genetic, morphological, chemical, and ecological variables (Melito et al., 2013a). Previous studies on Mediterranean myrtle populations demonstrated that intersimple sequence repeat and AFLP could discriminate the genotypes according to their geographic origin (Agrimonti et al., 2007; Bruna et al., 2007; Melito et al., 2013b). Among the genetic markers, the AFLPs have some advantages: a high level of reproducibility and the possibility to screen a large number of loci simultaneously without any sequence information. Concerning myrtle, much efforts have been dedicated to the characterization of its secondary metabolites (essential oils and polyphenols) (Mulas and Melis, 2011; Tuberoso et al., 2010), whereas little information is available on the environmental factors influencing the myrtle genetic diversity in Sardinia. For a new crop such as myrtle, the knowledge of the relationships between genetic resources and factors affecting the adaptability of the plant to different environmental conditions is necessary for the optimization of its management. In the present work, AFLP markers were applied with the aim to characterize from a genetic point of view some myrtle accessions previously selected for their fruit and biomass production properties. The genetic traits and the population genetic structure analysis were used to investigate the interrelationships between the genetic variation and the environmental factors with the aim to provide information about genetic diversity and structure distribution in different environmental conditions.

\section{Material and Methods}

Plant material and sampling sites. In this study, we analyzed a candidate cultivar collection of 33 Myrtus communis L. subsp. communis from Sardinia and one Myrtus communis subsp. tarentina (L.) Arcangeli (SAS1). The Sardinian genotypes studied were selected from the collection of the Department of Nature and Land Sciences of the University of Sassari, located at the "Antonio Milella" experimental station in Oristano in the midwest coast of Sardinia, Italy (lat. $39^{\circ} 53^{\prime} \mathrm{N}$, long. $8^{\circ} 37^{\prime} \mathrm{E}, 11 \mathrm{~m}$ above sea level, $10 \mathrm{~km}$ from the sea). Such a collection is the result of a selection program, based on few morphological traits (see subsequently), 
aimed at identifying, throughout Sardinia, genotypes with good biomass and fruit production (Mulas et al., 2002). The origin of each accession, the accession code, the longitude, the latitude, the altitude, and the soil type of each collection area are reported in Table 1. roughly $10 \mathrm{~cm}$ in length were collected, placed on ice in plastic bags, and taken to the laboratory. Samples were stored at $-20^{\circ} \mathrm{C}$ until the DNA extraction was performed.

Morphological analysis. Morphological and biometrical data were recorded for each
From each individual, young branches

accession. Thirty offshoots for each ecotype were selected and the following traits were measured: shoot length $(\mathrm{cm})$, internode number per shoot $(\mathrm{n})$, internode length $(\mathrm{cm})$, leaf length, and width $(\mathrm{cm})$. Pairwise correlation (from a multivariate platform) was performed among the morphological and biometrical data using JMP 7 software (SAS Institute, Cary, NC).

DNA extraction and AFLP procedure. Total genomic DNA was extracted from $100 \mathrm{mg}$ of young leaves using the DNeasy ${ }^{\circledR}$ Plant mini kit (QIAGEN, Hilden, Germany) following the supplier's instructions. DNA

Table 1. Characteristics of myrtle sampling localities. ${ }^{z}$

\begin{tabular}{|c|c|c|c|c|c|}
\hline \multirow[b]{2}{*}{ Sampling localities } & \multirow[b]{2}{*}{ Code } & \multicolumn{2}{|c|}{ Coordinates } & \multirow[b]{2}{*}{ Altitude (m) } & \multirow[b]{2}{*}{ Soil type } \\
\hline & & Latitude & $\overline{\text { Longitude }}$ & & \\
\hline Siniscola & $\operatorname{Sin} 2$ & $40^{\circ} 34^{\prime} 39^{\prime \prime} \mathrm{N}$ & $9^{\circ} 41^{\prime} 23^{\prime \prime} \mathrm{E}$ & 20 & Schist \\
\hline Telti & Tel2 & $40^{\circ} 52^{\prime} 47^{\prime \prime} \mathrm{N}$ & $9^{\circ} 21^{\prime} 20^{\prime \prime} \mathrm{E}$ & 332 & Granite \\
\hline Olia Speciosa & Sbd1 & $39^{\circ} 16^{\prime} 38^{\prime \prime} \mathrm{N}$ & $9^{\circ} 31^{\prime} 36^{\prime \prime} \mathrm{E}$ & 239 & Granite \\
\hline & $6 \_2$ & $39^{\circ} 16^{\prime} 38^{\prime \prime} \mathrm{N}$ & $9^{\circ} 31^{\prime} 36^{\prime \prime} \mathrm{E}$ & 239 & Granite \\
\hline Bosa & $\begin{array}{l}\text { Bos1 } \\
\text { Bos2 }\end{array}$ & $40^{\circ} 20^{\prime} 06^{\prime \prime} \mathrm{N}$ & $8^{\circ} 22^{\prime} 51^{\prime \prime} \mathrm{E}$ & 13 & Sandstone \\
\hline Budoni & Bud1 & $40^{\circ} 42^{\prime} 11^{\prime \prime} \mathrm{N}$ & $9^{\circ} 42^{\prime} 35^{\prime \prime} \mathrm{E}$ & 24 & Granite \\
\hline Uta-Monte Arcosu & $\begin{array}{l}\text { Cpt3 } \\
\text { Cpt4 } \\
\text { Cpt5 } \\
\text { Cpt6 }\end{array}$ & $39^{\circ} 11^{\prime} 20^{\prime \prime} \mathrm{N}$ & $8^{\circ} 56^{\prime} 08^{\prime \prime} \mathrm{E}$ & 54 & Granite/schist \\
\hline Cuglieri & Cug11 & $40^{\circ} 11^{\prime} 18^{\prime \prime} \mathrm{N}$ & $8^{\circ} 33^{\prime} 57^{\prime \prime} \mathrm{E}$ & 284 & Basalt \\
\hline Isili & Isl1 & $39^{\circ} 44^{\prime} 23^{\prime \prime} \mathrm{N}$ & $9^{\circ} 06^{\prime} 61^{\prime \prime} \mathrm{E}$ & 523 & Basalt \\
\hline Laconi & $\begin{array}{l}\text { Lac1 } \\
\text { Lac10 } \\
\text { Lac11 } \\
\text { Lac3 } \\
\text { Lac31 }\end{array}$ & $39^{\circ} 51^{\prime} 07^{\prime \prime} \mathrm{N}$ & $9^{\circ} 03^{\prime} 09^{\prime \prime} \mathrm{E}$ & 637 & Schist \\
\hline Monti & $\begin{array}{l}\text { Mon2 } \\
\text { Mon4 }\end{array}$ & $40^{\circ} 48^{\prime} 04^{\prime \prime} \mathrm{N}$ & $9^{\circ} 19^{\prime} 29^{\prime \prime} \mathrm{E}$ & 296 & Granite \\
\hline Orosei & $\begin{array}{l}\text { Oro2 } \\
\text { Ors2 } \\
\text { Ors3 }\end{array}$ & $40^{\circ} 22^{\prime} 21^{\prime \prime} \mathrm{N}$ & $9^{\circ} 41^{\prime} 50^{\prime \prime} \mathrm{E}$ & 19 & Granite \\
\hline Parco dei sette fratelli & $\begin{array}{l}\text { Psf1 } \\
\text { Psf4 }\end{array}$ & $39^{\circ} 20^{\prime} 29^{\prime \prime} \mathrm{N}$ & $9^{\circ} 13^{\prime} 04^{\prime \prime} \mathrm{E}$ & 423 & Granite \\
\hline Rumanedda & $\begin{array}{l}\text { Rub } \\
\text { Rum15 } \\
\text { Rum20 } \\
\text { Rum12 } \\
\text { Rum13 } \\
\text { Rum14 } \\
\text { Rum3 } \\
\text { Rum4 } \\
\text { Rum6 }\end{array}$ & $40^{\circ} 40^{\prime} 56^{\prime \prime} \mathrm{N}$ & $8^{\circ} 21^{\prime} 38^{\prime \prime} \mathrm{E}$ & 100 & Limestone \\
\hline
\end{tabular}

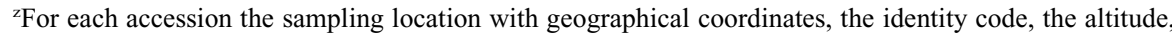
and the soil type are reported. quality and concentration were estimated by spectrophotometric analysis and by comparison, on a $0.8 \%(\mathrm{w} / \mathrm{v})$ agarose gel, with a known amount of $\lambda$ DNA.

AFLP analysis was carried out according to Vos et al. (1995) with few minor modifications. Briefly, genomic DNA (250 ng) was double-digested for $1 \mathrm{~h}$ at $37^{\circ} \mathrm{C}$ in a final volume of $40 \mu \mathrm{L}$ with $E c o R I$ (5U) and MseI $(5 \mathrm{U})$ in $10 \times$ Restriction/Ligation $(\mathrm{R} / \mathrm{L})$ buffer (100 mm Tris base, $100 \mathrm{~mm} \mathrm{MgAc,} 500 \mathrm{~mm}$ KAc, $50 \mathrm{~mm}$ DTT, $100 \mathrm{ng} / \mu \mathrm{L}$ bovine serum albumin). Ten microliters of ligation mix $(5 \mu \mathrm{M}$ EcoRI adapters + 1A, $50 \mu \mathrm{M}$ MseI adapters + 1C, $10 \mathrm{~mm}$ adenosine-5' ${ }^{\prime}$-triphosphate, $1 \mathrm{U}$ T4 ligase) were added to the restriction mix and incubated for $3 \mathrm{~h}$ at $37{ }^{\circ} \mathrm{C}$. Restriction enzymes and T4 ligase were purchased from New England Biolabs (Ipswich, MA). Five microliters of R/L mixture (diluted 1:9) were used in $20 \mu \mathrm{L}$ of the pre-amplification mix. The pre-amplification was conducted by adding $1.5 \mathrm{~mm} \mathrm{MgCl}_{2}, 10 \times$ Buffer, $10 \mathrm{~mm}$ dNTPs, $2.75 \mu \mathrm{M}$ EcoRI Primer, $2.75 \mu \mathrm{M}$ MseI Primer, and $1 \mathrm{U} \mathrm{Taq}$ polymerase.

The pre-amplification polymerase chain reaction $(\mathrm{PCR})$ product was diluted 1:4 with sterile water and $5 \mu \mathrm{L}$ were used as a template for selective PCR by adding $10 \times$ PCR Buffer, $1.5 \mathrm{mM} \mathrm{MgCl}_{2}, 10 \mathrm{~mm}$ dNTPs, $0.46 \mu \mathrm{M}$ EcoRI $+3 \mathrm{~N}$ primer, $2.75 \mu \mathrm{M} M s e \mathrm{I}+3 \mathrm{~N}$ primer, and $1 \mathrm{U} \mathrm{Taq}$ polymerase in $20-\mu \mathrm{L}$ final volume. Four EcoRI/MseI primer combinations with three selective nucleotides were used (Table 2).

All PCRs were performed using Platinum $^{\circledR}$ Taq DNA Polymerase High Fidelity. Pre-amplification and selective amplification cycles were carried out according to Vos et al. (1995).

AFLP-PCR products were separated by electrophoresis on $6 \%$ denaturing polyacrylamide gels along with the 100-bp DNA Ladder 100 (Invitrogen Life Technologies) to determine the sample band sizes. Gels were silver-stained according to Bassam et al. (1991) with the following modifications: $20 \mathrm{~min}$ fixer solution ( $10 \%$ glacial acetic acid, two 5 -min washes in distilled water), $30 \mathrm{~min}$ staining in $0.2 \%$ silver nitrate, $3 \mathrm{~mL} \cdot \mathrm{L}^{-1}$ formaldehyde, 10 -s wash in distilled water, and revelation in a $4{ }^{\circ} \mathrm{C}$ pre-cooled solution containing sodium carbonate $\left(30 \mathrm{~g} \cdot \mathrm{L}^{-1}\right)$, formaldehyde $\left(0.35 \mathrm{~mL} \cdot \mathrm{L}^{-1}\right)$, and sodium thiosulfate $\left(0.05 \mathrm{~g} \cdot \mathrm{L}^{-1}\right)$. The gel development

Table 2. Primer sets used for pre-selective and selective amplification for amplified fragment length polymorphism fingerprinting. ${ }^{\mathrm{z}}$

\begin{tabular}{|c|c|c|c|}
\hline Primer sequence for pre-selective amplification & Primer sequence for selective amplification & Monomorphic alleles (\%) & Unique alleles $(\%)$ \\
\hline EcoRI + 1A 5'GACTGCGTACCAATTCA-3' & EcoRI 01 GACTGCGTACCAATTCAAC & 14 & 20 \\
\hline \multirow[t]{9}{*}{ MseI + 1C 5'-GATGAGTCCTGAGTAAC-3' } & Mse I 01 GATGAGTCCTGAGTAACTG & & \\
\hline & EcoRI 01 GACTGCGTACCAATTCAAC & & \\
\hline & Mse I 02 GATGAGTCCTGAGTAACAT & & \\
\hline & EcoRI 01 GACTGCGTACCAATTCAAC & & \\
\hline & Mse I 03 GATGAGTCCTGAGTAACTA & & \\
\hline & EcoRI 03 GACTGCGTACCAATTCAGC & & \\
\hline & Mse I 03 GATGAGTCCTGAGTAACTA & & \\
\hline & EcoRI 02 GACTGCGTACCAATTCACC & ND & ND \\
\hline & Mse I 02 GATGAGTCCTGAGTAACAT & & \\
\hline
\end{tabular}

${ }^{\mathrm{z}}$ Number of fragment, percentage of monomorphic, and unique alleles are also reported.

$\mathrm{ND}=$ no data. 
was stopped by incubating in $10 \%$ acetic acid for $1 \mathrm{~min}$. Gels were rinsed for $5 \mathrm{~min}$ and dried overnight at room temperature. PCR amplification was repeated twice to ensure the consistency of the AFLP profile.

Dried polyacrylamide gels were manually analyzed for presence (1) or absence (0) of bands. Only clearly amplified fragments were scored; bands with a weak signal or blurred appearance were not considered.

Data analysis. Genetic population structure was investigated using the Bayesian clustering model implemented in STRUCTURE 2.3.3 (Pritchard et al., 2000). The software was run without a priori information on population membership, assuming admixture and correlated allele frequencies and a recessive genotype mode. Cluster numbers $(K)$ ranged from one to 10 , and for each $K$, 20 replicate chains of 200.000 Markov Chain Monte Carlo interactions with a length of burn-in period of 100.000 were run. The attribution of each sample to a specific cluster was based on a coefficient of membership $(Q)$. The optimal $K$ was calculated according to Evanno et al. (2005).

Estimation of polymorphic alleles number, genetic diversity value $(\mathrm{He})$, and fixation index $\left(F_{S T}\right)$ for each population considered were calculated by Arlequin Version 3.5.1.2 (Excoffier et al., 2005).

The analysis of population divergence was carried out by analysis of molecular variance (AMOVA) as implemented in Arlequin Version 3.5.1.2 (Excoffier et al., 2005).

Population genetic distance matrix (Nei, 1973) was performed with Arlequin to explore the pairwise relationships among the M. communis accessions analyzed. A further analysis based on distance matrix among candidate cultivars was performed to discriminate plants according to their sampling site altitude.

A phylogenetic tree was designed based on UPGMA clustering (Nei, 1978) using TFPGA Version 1.3 software. Spearman correlation analysis was performed by JMP 7 software (SAS Institute, Cary, NC) to assess the relationships among environmental variables (altitude and soil), morphological traits, and population genetic cluster assignment coefficient of membership $(Q)$.

\section{Results and Discussion}

Morphological traits. Previous works (Mulas et al., 2002; Mulas and Cani, 1999) highlighted the high variability of Sardinian myrtle accessions based on morphological parameters. The pool of candidate cultivars studied in this article is the result of a selection work started with the mass selection from the wild populations of 130 accessions. All accessions were characterized by high spring shoot length, leaf size, internode number, and length. Those characters were related to fruit and biomass production. In fact, spring shoot vigor and length are linked to a strong possibility to observe abundant flower bud differentiation in the basal internodes. Moreover, a well-defined spring blossom flux avoids multiple plant flowering fluxes with negative effects on final yield (Mulas and Cani, 1999; Mulas and Fadda, 2004). In this article, we studied the correlations among such morphological traits as parameters associated with fruit or biomass production.

The candidate cultivar selections analyzed showed high positive correlations (Pearson; $P<0.0001$ ) among leaf (length and width) and internodes (length and number) (Table 3 ). Those findings were useful to confirm the effectiveness of the phenotypic selection process and to have a first basis to evaluate the effects in term of possible loss of genetic variability.

AFLP patterns. The AFLP profiling has been used to discriminate between closely related genotypes belonging to the same species and to evaluate the genetic diversity in wild species (Baldoni et al., 2006; Christensen et al., 2011; Erre et al., 2010; Turpeinen et al., 2001). The assessment of genetic diversity could be considered a useful instrument to identify selected genotypes for fruit or biomass yield in a breeding program.

The AFLP analysis of the myrtle candidate cultivars produced more than 100 fragments for the primer set, ranging from 40 to $700 \mathrm{bp}$. Fragments from 50 to $500 \mathrm{bp}$ were manually scored for 138 reproducible amplicons. Each primer generated a specific number of polymorphic bands. Primers set EcoRI 1/MseI 01 and EcoRI 1/MseI 03 generated the highest number of fragments (59 for each primer combination); the other two primer combinations, EcoRI 01/MseI 02 and EcoRI 03/MseI 03, produced, respectively, 15 and five fragments. Overall, we identified $14 \%$ of monomorphic markers and $20 \%$ of unique AFLP fragments (Table 2). All the unique amplicons were found in EcoRI 1/MseI 01 and EcoRI 1/MseI 03 primer combinations. To minimize the AFLP scoring errors, faint polymorphic bands were excluded. Control genotypes were used to align different run gels in the same primer combination and finally $10 \%$ of the samples were twice scored to assess the reproducibility of the scoring.

The analyzed myrtle candidate cultivars showed a high level of polymorphic markers (96\%). Similarly, in Tunisian myrtle populations, a high percentage of polymorphic loci was identified with random amplified polymorphic DNA and isozymes (Messaoud et al., 2006, 2007).

Table 3. Pairwise correlations coefficients among morphological traits of myrtle plants. ${ }^{\mathrm{z}}$

\begin{tabular}{llcc}
\hline Variable & By variable & Correlation coefficient & Significance $(P)$ \\
\hline Internode L & Internode N & -0.5032 & 0.0024 \\
Leaf L/W & Leaf W & -0.5315 & 0.0012 \\
Leaf L & Internode N & -0.4174 & 0.0141 \\
Leaf L & Internode L & 0.7821 & $<0.0001$ \\
Leaf W & Internode L & 0.6807 & $<0.0001$ \\
Leaf W & Leaf L & 0.8022 & $<0.0001$ \\
Internode N & Shot L & 0.7874 & $<0.0001$ \\
\hline
\end{tabular}

${ }^{\mathrm{z}}$ Shoot length, internode length and number, leaf length and width, and their ratio were analyzed.

$\mathrm{L}=$ length; $\mathrm{W}=$ width; $\mathrm{N}=$ number.
Population genetic structure. STRUCTURE analysis identified two main genetic groups $(K=2)$ referred as Cluster A (CA) and Cluster B (CB) (Fig. 1). The maximum likelihood value was observed at $K=2$ with a $\Delta K=35.48$ (Fig. 1A). The coefficient of membership $(Q)$ of each genotype is shown in Figure 1B. The two clusters showed different numbers of individuals. Most of the individuals belonged to Cluster B, whereas only eight genotypes were attributed to Cluster A. In addition, a group of ecotypes (LAC11, SIN2, RUM12, RUM15, and ORS2) showed a coefficient of membership lower than 0.60 . These myrtle accessions were not assigned to any specific genetic cluster and were defined as an "admixture." These admixed individuals may be the result of the gene flow between the two genetic clusters identified. The genotype SAS1, which is the only genotype of the subspecies tarentina, belonged to the smaller group, and it did not cluster separately as it is expected. Furthermore, a deeper analysis of the $\Delta K$ trend revealed a second pick at $K=3$ (Fig. 1A). This further division was explored for it high informative value. At $K=3$, the composition of Clusters A and B changed. Cluster A composition was quite respected except for two accessions: PSF4 (that became an admixed individual) and BUD1 (assigned to the new Cluster III). Cluster B underwent the deepest variation in genetic cluster assignment: more than $50 \%$ of the individuals were attributed to the "admixed group," whereas two of the admixed individuals (ORS2 and RUM15) were grouped into the new genetic cluster (III) identified. LAC11, SIN2, and RUM12 maintained an admixed genetic composition because of their low coefficient of membership ( $Q<$ 0.6) (Fig. 1B).

A detailed picture of myrtle accessions relationships was also studied by UPGMA clustering using Nei's (1978) index as distance matrices. The UPGMA dendrogram showed a partial congruence with the division observed with STRUCTURE analysis (Fig. 2). Five main groups can be identified in Figure 2. Branch I grouped all myrtle accessions belonging to Cluster B and it has clearly separated from the other myrtle accessions. Branch II and III included most of the Cluster A members The accessions PSF4 and BUD1, assigned to Clade II, were the only exception to the cluster assignments obtained at $K=2$. In addition, two genotypes, CPT6 and SAS1, 
were grouped in two separated and independent clusters.

The genotype SAS1, classified as $M$. communis subsp. tarentina, clustered separately into one independent branch. These data clearly showed the $M$. communis subsp. communis and the Myrtus communis subsp. tarentina division, thus confirming the reliability of the AFLP genotyping.

Genetic diversity. The genetic diversity $\mathrm{He}$ of the myrtle core collection studied ranged from 0.239 to 0.420 . The observed average heterozygosity $(\mathrm{He}=0.314)$, along with the high number of polymorphic loci

A

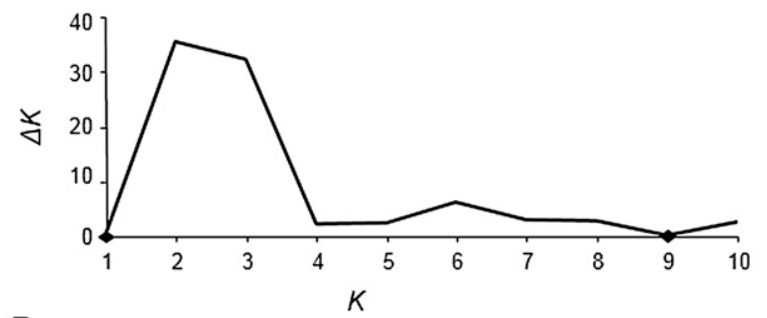

B
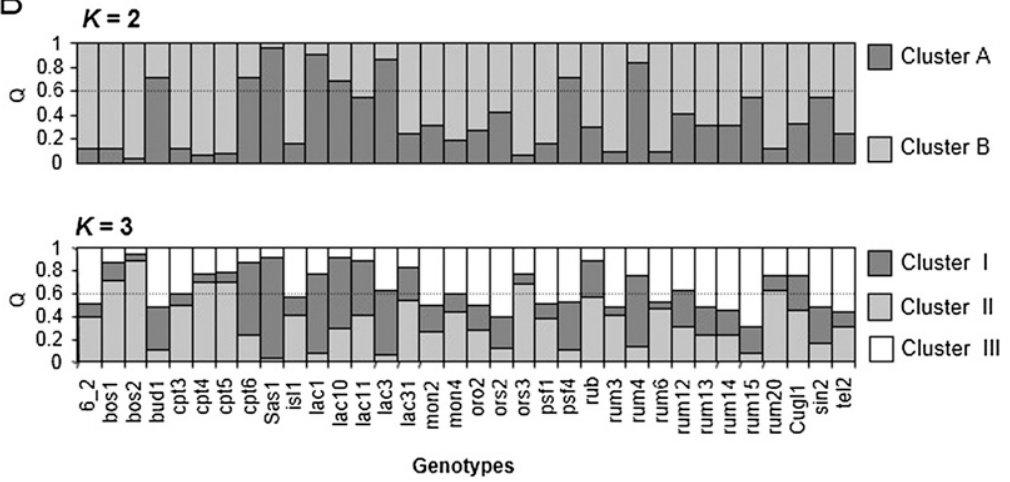

Fig. 1. Population structure of 33 Myrtus communis L. candidate cultivars. (A) Estimation of $\Delta K$ value obtained with STRUCTURE analysis; (B) myrtle accessions genetic group assignment based on Bayesian clustering model analysis. The average coefficient of membership $(Q)$ was calculated considering the partition of myrtle accessions into $2(\mathrm{~K}=2)$ and $3(\mathrm{~K}=3)$ clusters.

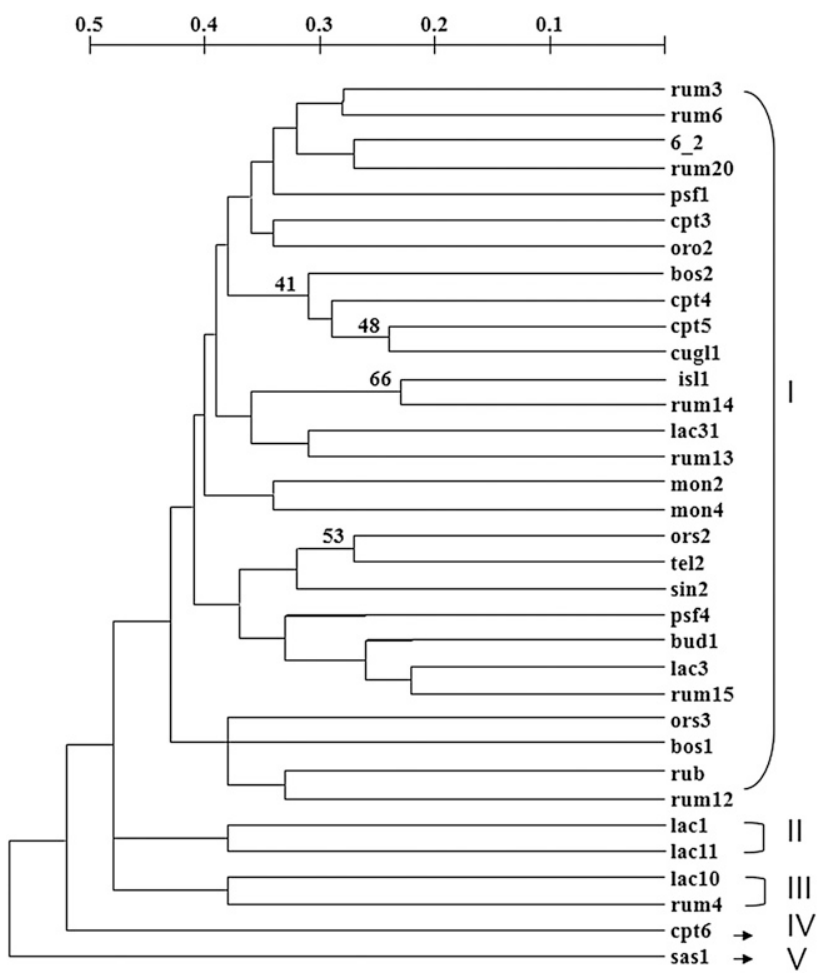

Fig. 2. Unweighted pair group method with averages cluster dendrogram, based on Nei's genetic distance, showing the genetic relationships among the $33 \mathrm{M}$. communis L. candidate cultivar selections.

(96\%), suggests a high genotypic richness of the original collected selections. Monti selection exhibited the lowest $\mathrm{He}$, whereas the highest value was assigned to Bosa myrtle selections. The levels of $\mathrm{He}$ reported in this study were higher than those observed by Agrimonti et al. (2007) in other Sardinian myrtle populations and by Messaoud et al. (2006) in Tunisian myrtle populations. Such low levels of genetic diversity reported in these works could be the result of a greater sample size and of a different collection strategy of the analyzed populations. Indeed, it should be emphasized that in our work, plants were not randomly selected but the selection was performed according to plant fruit and biomass productivity.

The levels of genetic diversity were confirmed by the $F_{S T}$ values. These were reported as pairwise distance matrix and displayed in Table 4. Mean $F_{S T}$ value, calculated among all myrtle candidate cultivars, was quite low (0.065), showing a small genetic distance among populations collected in the original sampling localities. The highest genetic distance was found between myrtle plants collected in Monti (north Sardinia) and Capoterra (south Sardinia) and between plants collected in Monti and Laconi (central Sardinia) $\left(F_{S T}\right.$ value of 0.146 and 0.181 , respectively). By contrast, the lowest genetic distance was recorded between Bosa and Olia Speciosa populations $\left(F_{S T}=-0.016\right)$. The $F_{S T}$ values found in sampling sites with the highest genetic distance demonstrated that populations were genetically different but not geographically isolated, thus suggesting a possible gene flow among these populations. These results pointed out that a geographical trend in the genetic differentiation among Sardinian myrtle populations may be present. Physical barriers such as mountains might influence the pollen dispersion, modifying the genetic exchanges between different sampling sites. The AMOVA was used to analyze the sources of genetic variance among or intra populations level (Table 5). Our AFLP-based AMOVA studies show that most of the genetic variation in myrtle is distributed within populations rather than among them, indicating a relatively restricted population differentiation as expected in mixed mating species. As shown in Table 5, $93.54 \%$ of the variability was within the population, whereas only $6.46 \%$ of the AFLP diversity was distributed among populations. According to Migliore et al. (2012), the homogeneity among Sardinian myrtle populations is the result of very recent expansion of this plant in Sardinia.

The AMOVA analysis was also used to explore the partition of the molecular variance at the cluster divisions identified by structure $(K=2 ; K=3)$. As expected, at $K=2$, the AMOVA revealed an increase of the percentage of genetic variation calculated within populations $(93.91 \%)$ This trend is also confirmed by the $F_{S T}$ value, which indicated the strongest genetic differentiation at $K=2\left(F_{S T}=0.0538\right)$ (Table 5). Taken together, these results suggest a low genetic 
distance among populations. These outcomes are compatible with the proportion of outcrossing of myrtle plants. Indeed, according to Gonzáles Varo et al. (2009), the differentiation among plant populations might be influenced by the plant mating pattern. As already reported, myrtle is mainly an outcrossing species with a proportion of selfpollination (Mulas and Fadda, 2004). A large variation of mating patterns has been observed among populations (Gonzáles Varo et al., 2009, 2010).

Genetic diversity and environmental parameters. The understanding of the relationships between the genetic diversity distribution and the ecological variables has a major role in biodiversity conservation strategies. In the case of myrtle, evidence on the impact of ecological parameters on the genetic variability may provide useful information about the adaptability of the selected accessions to different environmental and agronomical conditions. Altitude produces ecological barriers against the gene flow acting on the genetic selection and differentiation.

Local genetic differentiation, as a result of the altitude gradient, has been reported in different wild herbaceous species such as Helichrysum italicum (Melito et al., 2013a) and Elymus nutans (Yan et al., 2009), whereas little information is available about shrub and tree species. To the extent of our knowledge, little information is available on ecological factors affecting population genetic structure and distribution in Mirtaceae family, and almost no studies have been performed on M. communis.

In Sardinia, myrtle grows up to $800 \mathrm{~m}$ above the sea level (Mulas et al., 2002); however, the plants under study were collected up to a maximum altitude of $637 \mathrm{~m}$. For this reason, we decided to study the relationships between the model-based clusters and the genetic distribution in three different altitude levels (less than $100 \mathrm{~m}, 100$ to $200 \mathrm{~m}$, greater than $200 \mathrm{~m}$ a.s.l).

Plants belonging to Cluster A showed a greater distribution at high altitudes (Fig. 3B). Conversely, Cluster B members showed an opposite trend: individuals belonging to this group decreased their presence progressively with altitude (Fig. 3B). When evaluated with a partition of the plants into three genetic clusters $(K=3)$, it was observed that plants of the first (I) group were most common at altitudes above $200 \mathrm{~m}$, whereas plants of the second group (II) showed their greatest distribution at altitudes lower than $100 \mathrm{~m}$. The third genetic group, mainly identified as a partition of $\mathrm{CB}$ (Fig. 3B), revealed its maximum presence at altitudes ranging from $101 \mathrm{~m}$ to $200 \mathrm{~m}$ a.s.1, whereas it was less represented at altitudes from less than $100 \mathrm{~m}$ and greater than $200 \mathrm{~m}$ a.s.1 (Fig. 3B). The correlations between altitude and genetic cluster assignment $(Q)$ were statistically significant at $K=2$ (Pearson, $P=0.0285$ ), whereas at $K=3$, only Cluster I showed a significant correlation with altitude $(P=$ 0.0117 ). This outcome was also confirmed by
Table 4. Pairwise genetic distance matrix $\left(F_{s t}\right)$ among different localities with more the one myrtle accessions.

\begin{tabular}{|c|c|c|c|c|c|c|c|c|}
\hline & $\begin{array}{c}\text { Olia } \\
\text { Speciosa }\end{array}$ & Bosa & Capoterra & Laconi & Monti & Orosei & $\begin{array}{c}\text { Sette } \\
\text { fratelli }\end{array}$ & Rumanedda \\
\hline Olia Speciosa & 0 & & & & & & & \\
\hline Bosa & -0.0162 & 0 & & & & & & \\
\hline Capoterra & -0.0379 & 0.0344 & 0 & & & & & \\
\hline Laconi & 0.0915 & 0.1427 & 0.1147 & 0 & & & & \\
\hline Monti & 0.0993 & 0.0444 & $0.1459^{z}$ & 0.1813 & 0 & & & \\
\hline Orosei & -0.0731 & 0.0597 & 0.0301 & 0.0866 & 0.0596 & 0 & & \\
\hline Sette fratelli & -0.0541 & 0.0588 & 0.0489 & 0.0197 & 0.0541 & -0.0152 & 0 & \\
\hline Rumanedda & -0.0576 & 0.0973 & 0.1005 & 0.0479 & 0.1215 & 0.0209 & 0.0497 & 0 \\
\hline
\end{tabular}

${ }^{\mathrm{Z}}$ In bold are indicated the two highest genetic distances.

Table 5. Partition of genetic variation determined by AMOVA analysis. ${ }^{2}$

\begin{tabular}{llrccrr}
\hline & Sources of variation & df & Sum of squares & $\begin{array}{c}\text { Variance } \\
\text { components }\end{array}$ & $\begin{array}{c}\text { Percentage } \\
\text { of variation }\end{array}$ & $F_{\text {ST }}$ \\
\hline Overall & Among populations & 7 & 158.982 & 1.26941 & 6.46 & 0.065 \\
& Within populations & 21 & 385.811 & 18.37196 & 93.54 & \\
& Total & 28 & 544.793 & 19.64137 & & \\
Altitude & Among populations & 2 & 40.348 & 0.33019 & 1.96 & 0.0196 \\
& Within populations & 31 & 511.299 & 16.49351 & 98.04 & \\
& Total & 33 & 551.647 & 16.82370 & & \\
$K=2$ & Among populations & 1 & 28.731 & 0.93910 & 5.38 & 0.0538 \\
& Within population & 24 & 396.538 & 16.52244 & 94.62 & \\
& Total & 25 & 425.269 & 17.46154 & & \\
$K=3$ & Among populations & 2 & 49.597 & 0.795 & 4.68 & 0.0468 \\
& Within population & 31 & 502.050 & 16.195 & 95.32 & \\
& Total & 33 & 551.647 & 16.990 & & \\
\hline
\end{tabular}

${ }^{2}$ Altitude and population genetic structure at $K=2$ and $K=3$ were considered as sources of molecular variance. The overall AMOVA was also evaluated.

AMOVA $=$ analysis of molecular variance.
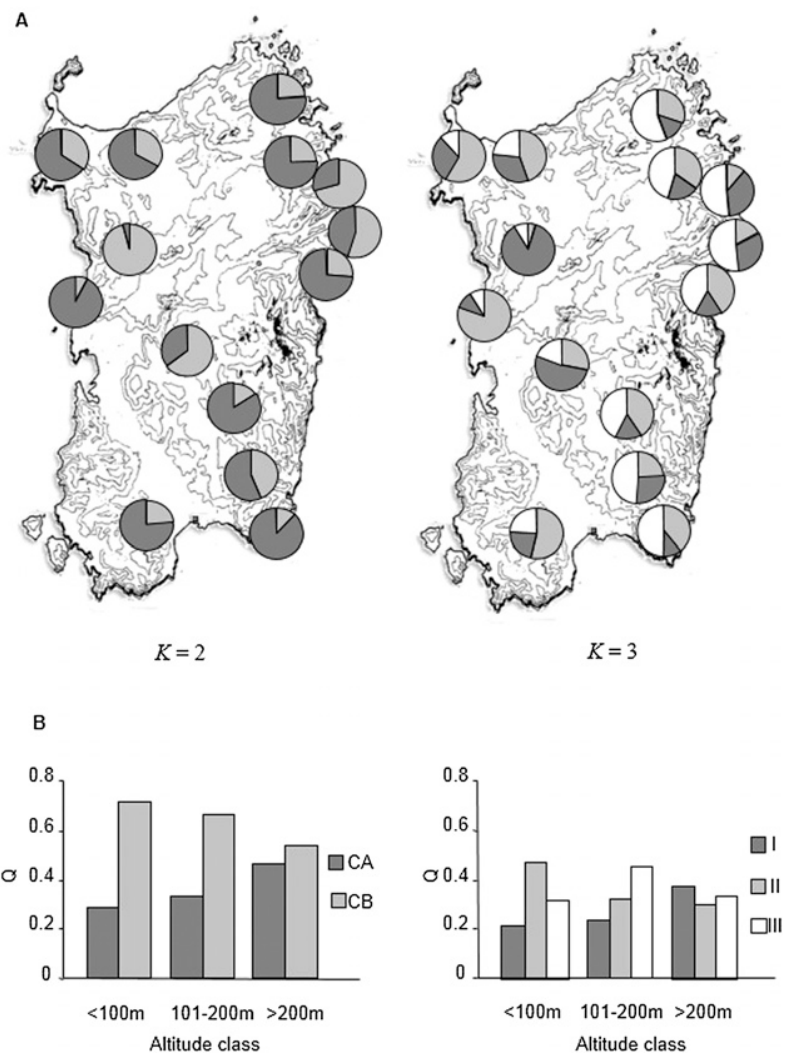

Fig. 3. Distribution of myrtle population clusters, as identified by STRUCTURE, according to geographical origin (A), and to altitude classes (B). Cluster membership was based on average coefficient of membership $(Q)$ calculated considering the population genetic structure at $K=2$ and at $K=3$. Colors refer to clusters: at $K=2$ deep gray $=$ Cluster A, pale gray $=$ Cluster B; at $K=3$ deep gray $=$ Cluster I, pale gray $=$ Cluster II, white $=$ Cluster III. 
the AMOVA analysis (Table 5), which showed that, when the molecular variance was calculated according to the altitude classes, the greatest part of the genetic variance was assigned "within populations" rather than among them (98.04\%). These results suggested a high adaptability of the plants under study to the different environmental conditions found at the altitude classes considered.

Our results confirm that environmental factors may act in the selection processes, suggesting that selection for adaptation at different altitudes levels may occur.

By contrast, when calculated independently from the cluster partition, pairwise $F_{S T}$ distance matrices showed a high level of genetic distance among the AFLP profile of individuals growing at the lowest and highest altitudes (data not shown).

The geographic distribution of hills and mountains in Sardinia prompted interesting questions on the relationships between genetic diversity distribution and the habitat contests. In Figure 3 is reported the distribution of the genetic variance considering the two cluster partition identified $(K=2$ and $K=$ 3 ), expressed as a coefficient of membership $Q$ for each myrtle population.

At $K=2$, the distribution of the genetic clusters did not show any geographical trend. Indeed, the geographic distribution of the genetic clusters identified at $K=3$ showed that the genetic group III increased its representativeness from west to east (Fig. 3A). This result was confirmed by the two $\times$ two contingency test performed between genetic clusters assignment and geographic origin (data not shown) $\left(\chi^{2}\right.$, Pearson $0.05, P=$ 0.0182 ). Similarly, the genetic clusters displayed a different distribution from north to south $\left(\chi^{2}\right.$, Pearson $\left.0.05, P=0.0032\right)$. The geographical trend observed in the distribution of the three clusters may be partially influenced by the position of the Sardinian mountains (distribution west-east) and by the long distance from north to south, which may have limited the gene flow. These data are compatible with the hypothesis of isolation by distance. These results are different from those obtained by Agrimonti et al. (2007), who found no significant correlations between the genetic variability and the geographical distance among myrtle populations sampled in Sardinia. In our opinion, such differences could lie on a lower size of our sample and difference in sampling strategy applied by these authors.

\section{Conclusions}

In Sardinia, myrtle populations are often subjected to overexploitation resulting from the intensive harvest of fruits and biomass for liqueur production (Mulas et al., 1999). Our results revealed a low genetic differentiation among populations, whereas a high genetic variability was observed within populations. These outcomes provide evidence of a certain resistance of the populations studied to genetic erosion as a result of excessive human pressure. Nevertheless, myrtle cultivation has been highly recommended to preserve natural populations (Mulas, 2012; Melito et al., 2013b). The measurement of the genetic diversity and the correlations between genetic variability and environmental factors may have important implications for the cultivation of the species. The genetic diversity and the structure of myrtle populations reported in this work demonstrated a different adaptability of the accession studied to environmental factors. The genetic clusters identified at two different levels of partition $(K=2$ and $K=3)$ showed that altitude represents an important factor acting on the myrtle population genetic diversity. Furthermore, a geographical trend was observed in the differentiation among Sardinian myrtle populations.

This work represents the first attempt to characterize, from a genetic point of view, some candidate cultivars selected, within the Sardinian germplasm, for fruit and biomass properties and production. Further studies will be necessary to build association maps of genetic, chemical, and agronomical traits.

\section{Literature Cited}

Agrimonti, C., R. Bianchi, M. Ballero, F. Poli, and N. Marmiroli. 2007. Understanding biological conservation strategies: A molecular-genetic approach to the case of myrtle (Myrtus communis L.) into Italian regions: Sardinia and Calabria. Conserv. Genet. 8:385-396.

Amar, M.H., M.K. Biswas, Z. Zhang, and W.W. Guo. 2011. Exploitation of SSR, SRAP and CAPSSNP markers for genetic diversity of citrus germplasm collection. Sci. Hort. 128:220-227.

Baldoni, L., N. Tosti, C. Ricciolini, A. Belaj, S. Arcioni, G. Pannelli, M.A. Germanà, M. Mulas, and A. Porceddu. 2006. Genetic structure of wild and cultivated olives in the Central Mediterranean basin. Ann. Bot. (Lond.) 98:935942.

Bassam, B.J., G. Caetano-Anollés, and P.M. Gresshoff 1991. Fast and sensitive silver straining of DNA in polyacrylamide gels. Anal. Biochem. 196:80-83.

Bruna, S., E. Portis, C. Cervelli, L. De Benedetti, T. Schiva, and A. Mercuri. 2007. AFLP-based genetic relationships in Mediterranean myrtle (Myrtus communis L.). Sci. Hort. 113:370-375.

Christensen, S., R. Bothmer, G. Poulsen, L. Maggioni, M. Phillip, B. Andersen, and R. Jørgensen. 2011. AFLP analysis of genetic diversity in leafy kale [Brassica oleraceaea $\mathrm{L}$. convar. acephala $(\mathrm{Dc})$ Alef] landraces, cultivars and wild populations in Europe. Genet. Resources Crop Evol. 58:657-666.

Deriu, A., G. Branca, P. Molicotti, G. Pintore, M. Chessa, B. Tirillini, M. Paglietti, A. Mura, L.A. Sechi, G. Fadda, and S. Zanetti. 2007. In vitro activity of essential oil of Myrtus communis L. against Helicobacter pylori. Intl. J. Antimicrob. Agents 30:562-563.

Erre, P., I. Chessa, C. Muñoz-Diez, A. Belaj, L. Rallo, and I. Trujillo. 2010. Genetic diversity and relationships between wild and cultivated olives (Olea europaea L.) in Sardinia as assessed by SSR markers. Genet. Resources Crop Evol. 57:41-54.

Evanno, G., S. Reganut, and J. Goudet. 2005. Detecting the number of clusters of individuals using the software structure: A simulation study. Mol. Ecol. 14:2611-2620.

Excoffier, L., G. Laval, and S. Schneider. 2005. Arlequin (version 3.0): An integrated software package for population genetics data analysis. Evol Bioinform 1:47-50.
Gonzáles-Varo, J.P., R.G. Albaladejo, and A. Aparicio. 2009. Mating patterns and spatial distribution of conspecific neighbours in the Mediterranean shrub Myrtus communis (Myrtaceae). Plant Ecol. 203:207-215.

Gonzáles-Varo, J.P., R.G. Albaladejo, A. Aparicio, and J. Arroyo. 2010. Linking genetic diversity, mating patterns and progeny performance in fragmented populations of a Mediterranean shrub. J. Appl. Ecol. 47:1242-1252.

Gündüz, G.T., Ş.A. Gönül, and M. Karapinar. 2009. Efficacy of myrtle oil against Salmonella thyphimurium on fresh produce. Intl. J. Food Microbiol. 130:147-150.

Kalia, R.K., M.K. Rai, S. Kalia, R. Sing, and A.K. Dhawan. 2011. Microsatellite markers: An overview of the recent progress in plants. Euphytica 177:309-334.

Melito, S., A. Sias, G.L. Petretto, M. Chessa, G. Pintore, and A. Porceddu. 2013a. Genetic and metabolite diversity of Sardinian populations of Helichrysum italicum. PLoS One 8:E79043.

Melito, S., I. Chessa, P. Erre, J. Podani, and M. Mulas. 2013b. The genetic diversity of Sardinian myrtle (Myrtus communis L.) populations. Electr $\mathrm{J}$ of Biotec 16:1-14.

Messaoud, C., M. Khoudja, and M. Boussaid. 2006. Genetic diversity and structure of wild Tunisian Myrtus communis L. (Myrtaceae) populations. Genet. Resources Crop Evol. 53:407-417.

Messaoud, C., M. Afif, A. Boulila, M.N. Rejeb, and M. Boussaid. 2007. Genetic variation of Tunisian Myrtus communis L. (Myrtaceae) populations assessed by isozymes and RAPDS. Ann. Sci. 64:845-853.

Migliore, J., A. Baumel, M. Juin, and F. Médail. 2012. From Mediterranean shores to central Saharan mountains: Key geographical insights from the genus Myrtus. J. Biogeogr. 39:942-956.

Mulas, M. 2012. The myrtle (Myrtus communis L.) case, from a wild shrub to a new fruit crop. Acta Hort. 948:235-242.

Mulas, M. and M.R. Cani. 1999. Germplasm evaluation of spontaneous myrtle (Myrtus communis L.) for cultivar selection and crop development. J. Herbs Spices Med. Plants 6:31-49.

Mulas, M., M.R. Cani, N. Brigaglia, and P. Deidda. 1999. Study of myrtle (Myrtus communis L.) genetic resources to promote extensive crop as integration of spontaneous harvest. Acta Hort. 502:85-88.

Mulas, M. and P. Deidda. 1998. Domestication of woody plants from Mediterranean maquis to promote new crops for mountain lands. Acta Hort. 457:295-301.

Mulas, M. and A. Fadda. 2004. First observation on biology and organ morphology of myrtle (Myrtus communis L.) flower. Agr Med 134:223-235.

Mulas, M., A.H.D. Francesconi, and B. Perinu. 2002. Myrtle (Myrtus communis L.) as a new aromatic crop: Cultivar selection. J. Herbs Spices Med. Plants 9:127-131.

Mulas, M. and R.A.M. Melis. 2011. Essential oil composition of Myrtle (Myrtus communis L.) leaves. J. Herbs Spices Med. Plants 17:21-34.

Nei, M. 1973. Analysis of gene diversity in subdivided populations. Proc. of the National Academy of Sciences of the United States of America 70.

Nei, M. 1978. Estimation of average heterozygosity and genetic distance from a small number of individuals. Genet 89:583-590.

Osman, A.K., A.A. Abd El-Mageed, A.Q. Tawfik, and H.A. Mohammed. 2012. Genetic diversity among four Eucaliptus species (Myrtaceae) based on random amplified polymorphic DNA (RAPD) analysis. Afr. J. Biotechnol. 11:4729-4739.

Pritchard, J.K., M. Stephens, and P. Donnelly. 2000. Inference of population structure using 
multilocus genotype data. Genet. 155:945959.

Tretiakova, I., D. Blaesius, L. Maxia, S. Wesselborg, K. Schlze-Osthoff, J. Cinatl, M. Michaelis, and O. Werz. 2008. Myrtucommulone from Myrtus communis induces apoptosis in cancer cells via the mitochondrial pathway involving capsase-9. Apoptosis 13:119-131.

Tuberoso, C.I.G., A. Rosa, E. Bifulco, M.P. Melis, A. Atzeri, F.M. Pirisi, and M.A. Dessi. 2010.
Chemical composition and antioxidant activities of Myrtus communis L. berries extracts. Food Chem. 123:1242-1251.

Turpeinen, T., T. Tenhola, O. Manninen, E. Nevo, and E. Nissilä. 2001. Microsatellite diversity associated with ecological factors in Hordeum spontaneum populations in Israel. Mol. Ecol. 10:1577-1591.

Vos, P., R. Hogers, M. Bleeker, M. Reijans, T.V.D. Lee, M. Hornes, A. Friters, J. Pot, J. Paleman,
M. Kiuper, and M. Zebeau. 1995. AFLP: A new technique for DNA fingerprinting. Nucleic Acids Res. 23:4407-4414.

Yan, X.B., Y.X. Guo, C. Zhao, F.Y. Liu, and B.R. Lu. 2009. Intra-population genetic diversity of two wheatgrass species along altitude gradients on the Quinghai-Tibetan plateau: Its implications for conservation and utilization. Conserv. Genet. 10:359367. 